\title{
Comparação de três técnicas de produção do antígeno do lentivírus caprino utilizado no teste de imunodifusão em gel de ágar
}

Raymundo Rizaldo PINHEIRO $^{1}$

Aurora Maria Guimarães GOUVEIA

Eliane Harumi YORINORI ${ }^{3}$ Alice ANDRIOLI'

\section{Correspondência para:}

RAYMUNDO RIZALDO PINHEIRO

EMBRAPA Caprinos

Estrada Sobral-Groaíras, Km 04

62011-970 - Sobral - CE

rizaldo@cnpc.embrapa.br

Recebido para publicação: 09/12/2003 Aprovado para publicação: 29/09/2005

\author{
1 - Embrapa Caprinos, Sobral - CE \\ 2 - Escola de Veterinária da Universidade Federal de Minas Gerais, Belo \\ Horizonte - MG \\ 3 - Médica Veterinária - Autônoma
}

\section{Resumo}

Palavras-chave Caprino. Lentivírus.

A Artrite Encefalite Caprina (AEC) é uma enfermidade que causa perdas econômicas consideráveis, incluindo perda na produção de leite e diminuição da vida útil do animal. No diagnóstico desta enfermidade o teste de imunodifusão em gel de ágar (IDGA) é utilizado mundialmente como o teste de triagem. Este trabalho teve como objetivo testar três diferentes concentrações de soro fetal bovino (SFB) na produção do antígeno (Ag) para o diagnóstico da AEC, verificar dentre três métodos o mais eficiente para efetuar a concentração e qual a concentração do antígeno produzido mais apropriada para o teste. Tanto o método do AMICON, como o da concentração do Ag por diálise são indicados, entretanto o sistema AMICON, apesar dos custos de implantação, promoveu menor perda de antígeno, maior rapidez e praticidade. Com relação à quantidade de soro fetal bovino (SFB) colocada após a inoculação viral observou-se que $5 \%$ de SFB foi a quantidade que apresentou melhores resultados. A concentração do antígeno mais indicada é de 100 vezes, pois permite a detecção de anticorpos contra o vírus da AEC (LVC) por duas proteínas (gp 135 e p28). A purificação do Ag por precipitação/ ultracentrifugação, utilizada para provas imunoenzimáticas (ELISA e Dot-BLOT), não apresentou resultados satisfatórios para o IDGA.

\section{Introdução}

O Lentivírus caprino é um retrovírus da subfamília Lentiviridae que causa a ArtriteEncefalite Caprina (AEC), uma enfermidade crônica e multissistêmica. Esta doença causa perdas econômicas consideráveis, incluindo queda na produção de leite, diminuição da vida útil e aumento da mortalidade de cabrito nascido de cabras infectadas. Além do aspecto econômico, o estudo da infecção tem despertado interesse devido a semelhanças biológicas e patogenéticas com o vírus da Síndrome da Imunodeficiência Adquirida (AIDS) ${ }^{1}$. No diagnóstico desta enfermidade o teste de imunodifusão em gel de ágar (IDGA) é utilizado mundialmente como o teste de triagem devido ao custo relativamente baixo, a razoável sensibilidade e especificidade, além da praticidade de execução e leitura ${ }^{2}$.

No Brasil, o diagnóstico do lentivírus caprino (LVC) é realizado quase que exclusivamente pelo teste de IDGA e com antígeno (Ag) heterólogo (Maedi- Visna) o que reduz a sensibilidade do teste. Segundo Knowles et al. ${ }^{3}$, se o antígeno for produzido com LVC a sensibilidade do teste seria provavelmente maior em até 35\% devido ao uso de antígeno homólogo 4 .

Este trabalho teve como objetivo produzir um antígeno nacional utilizando diferentes quantidades de soro fetal bovino na produção do antígeno, verificar dentre os três métodos o mais eficiente em termos de concentração e qual a concentração do 
antígeno produzido é mais apropriada para o teste.

\section{Materiais e Métodos}

\author{
Cultivo primário de células de membrana sinovial \\ caprina
}

Foram utilizados cultivos secundários de células de membrana sinovial caprina (MSC) obtidas a partir de cabrito comprovadamente negativo para LVC e submetidos a subcultivos por tripsinização das células ${ }^{5}$.

\section{Produção do Antígeno}

\section{Vírus}

Utilizou-se amostra do vírus CAEVCork (Amostra viral gentilmente cedida pela UFRPE, oriunda do Laboratoire Associé de Recherches sur les Petits Ruminants - INRA ENVL - France) com título de $10^{4,5}$ TCID $_{50}\left(\right.$ Tissue Culture Infectious Dose $\left._{50 \%}\right) /$ mL multiplicada em MSC.

\section{Titulação do vírus}

Titularam-se as amostras virais em microplacas por diluições decimais em meio essencial mínimo (MEM) sem soro fetal bovino (SFB), utilizando-se oito repetições por diluição. Em cada diluição foram colocados $50 \mathrm{~mL}$ da diluição viral, a qual permaneceu por uma hora a $37^{\circ} \mathrm{C}$ em $5 \%$ de atmosfera de $\mathrm{CO}$ Adicionaram-se $50 \mathrm{~mL}$ da suspensão de células de MSC obtidas por tripsinização, contendo 3,0 × $10^{4}$ células $/ \mathrm{cm}^{3}$ em MEM com $10 \%$ de SFB. Os poços controle de vírus e do cultivo continham respectivamente, a diluição do vírus e meio de cultivo, a suspensão celular, e o meio de cultivo. O título calculado segundo Reed e Muench ${ }^{7}$, definiu-se como a recíproca da diluição que apresentou, 14 dias após inoculação, sincícios em 50\% dos poços inoculados, e definido como uma dose formadora de sincício (DFS).

Cultivo da MSC e inoculação viral

$\mathrm{Na}$ produção viral as monocamadas semiconfluentes de MCS cultivadas em garrafas roller de $830 \mathrm{~cm}^{2}$ de superfície de cultivo, foram inoculadas 72 a 96 horas após passagem, com a monocamada contendo de 70 a $90 \%$ de confluência, com $15 \mathrm{~mL}$ de solução viral e com 200 DFS diluídas em MEM sem SFB ${ }^{8}$.

\section{Quantidade de Soro Fetal Bovino}

Após 60 minutos da inoculação viral adicionaram-se $135 \mathrm{~mL}$ de MEM com três diferentes concentrações de soro fetal bovino $0 \%, 2 \%$ e $5 \%$. Coletou-se o sobrenadante $(\mathrm{SN})$ por 3 vezes ou até a destruição de $75 \%$ da monocamada. Os sobrenadantes coletados, bem como as garrafas na última coleta, foram congeladas $\mathrm{a}-80^{\circ} \mathrm{C}$.

\section{Concentração do Antígeno}

Antes de ser concentrado o SN foi submetido a dois ciclos de congelamento e a clarificação por centrifugação a $3300 \mathrm{~g}$ a $4^{\circ} \mathrm{C}$. O SN foi concentrado a partir de três técnicas:

Diálise contra polietilenoglicol (PEG) - A concentração por diálise foi realizada conforme metodologia descrita por Cutlip et al. ${ }^{9}$ e constituiu-se na colocação do SN em membrana de diálise com cut-off de 12000 Daltons e dialisado contra PEG 6000 a 10\% em Tampão fosfato (PBS - 0,05M; $0,15 \mathrm{M} \mathrm{NaCl}$; pH 7,4$)$ à $4^{\circ} \mathrm{C}$ por 24 a 48 horas.

Ultrafiltração - No sistema AMICON aplicou-se pressão do gás nitrogênio diretamente à célula de ultrafiltração modelo 8400 da Millipore ${ }^{\circledR}$ conforme determinação do Fabricante ${ }^{10}$. Solutos acima do peso molecular de retenção "cut-off” da membrana (10000 Daltons) foram retidos na câmara, enquanto solutos abaixo do "cut-off" saíram para o filtrado. Nas duas técnicas concentrou-se 50X, 100X e 150X do volume inicial.

Precipitação e Ultracentrifugação - Esta técnica foi descrita por Houwers, Gilkens e Jan Schaake ${ }^{11}$ e constituiu-se em precipitação 
da suspensão clarificada, com PEG-8000 a $40 \%$ até a concentração final de $8 \%$, por 18 horas a 4C e centrifugação a $12000 \mathrm{~g}$ por 60 min a $4^{\circ} \mathrm{C}^{17}$. O sedimento foi suspenso em TNE $(10,0 \mathrm{mM}$ Tris- $\mathrm{HCl}, \mathrm{pH}$ 7,4; 10,0 mM $\mathrm{NaCl} ; 1,0 \mathrm{mM}$ EDTA) na proporção de $1 / 10$ do volume original da suspensão viral. A suspensão foi passada em colchão de sacarose $(25 \%$ em TNE) através de centrifugação 42000g (Beckman rotor SW 50.1 ) por $120 \mathrm{~min}$ a $4 \mathrm{oC}$ (Houwers et al. 1982). Utilizou-se em cada tubo de centrífuga: $1 \mathrm{~mL}$ de sacarose para $4 \mathrm{~mL}$ de suspensão viral. $O$ novo sedimento foi suspenso em PBS (volume igual a $0,5 \%, 1 \%$ e $1,5 \%$ do volume inicial de suspensão $=10$ $\mathrm{mL}$ ), contendo $2 \times 10^{-4}$ Molar de PMSF (Phenylmethylsulphonyl fluoride).

\section{Teste de Imunodifusão em Gel de Ágar - IDGA}

Foi utilizada a microtécnica de IDGA descrita por Gouveia et al. ${ }^{13} \mathrm{em}$ agarose a 0,9\% em tampão borato, utilizando $30 \mathrm{ml}$ de soro/antígeno, com a leitura realizada após 72 horas, com luz indireta sobre fundo escuro. Como controle utilizou-se soro positivo do kit americano para diagnóstico da AEC por IDGA [Caprine ArthritisEncephalitis/Ovine Progressive Pneumonia Antibody Test Kit. Veterinary Diagnostic Technology, Inc ${ }^{\circledR}$, USA. Este kit é composto por $1 \mathrm{~mL}$ de antígeno ( $\mathrm{p} 28$ e gp135) produzido com o
MVV, $3 \mathrm{~mL}$ de soro reagente (soro rico em anticorpos contra a glicoproteína gp135, 0,5 $\mathrm{mL}$ de soro positivo (soro rico em anticorpos contra as proteínas p28 e gp135), $0,5 \mathrm{~mL}$ de soro fraco-positivo (soro pobre em anticorpos contra a gp135 e sem anticorpos contra a p28) e soro negativo (soro sem anticorpos contra as proteínas p28 e gp135)].

\section{Resultados e Discussão}

As células sub-cultivadas com intervalos de 5 a 9 dias apresentaram níveis satisfatórios de vitalidade e produtividade por mais de 15 passagens. Os vírus, com título de $10^{4,5} \mathrm{TCID}_{50} / \mathrm{mL}$ multiplicaram-se bem, tanto em células de úm número baixo de passagens $\left(7^{a}\right.$ a $\left.8^{a}\right)$ como em células de num número elevado de passagens $\left(15^{\mathrm{a}} \mathrm{a}\right.$ $\left.16^{a}\right)$. Verificou que as células até a $20^{a}$ passagem permanecem com boa vitalidade e que o vírus se multiplica promovendo efeitos citopáticos (sincícios) até a $18^{a}$ passagem. Este dado é semelhante aos observados por Castro $^{6}$.

Na tabela 1 encontram-se os resultados obtidos no IDGA quando cruzados as concentrações do Ag, quantidade de SFB e o método de concentração. Com relação à quantidade de SFB aplicada após a inoculação viral verificou-se que 5\% de SFB

Tabela 1 - Formação de linhas de precipitação antígeno-anticorpo (Ag-Ac)sob a influência da quantidade de soro fetal bovino e do método de concentração do Antígeno. Sobral-Ceará, 2003* Verifica-se uma segunda linha entre o poço do Ag e do Ac considerada fraca

\begin{tabular}{|c|c|c|c|c|c|c|c|c|c|}
\hline \multirow{3}{*}{$\begin{array}{l}\text { Soro } \\
\text { Fetal } \\
\text { Bovino }\end{array}$} & \multicolumn{9}{|c|}{ Método de concentração / Taxa de concentração } \\
\hline & \multicolumn{3}{|c|}{ AMICON } & \multicolumn{3}{|c|}{ Diálise } & \multicolumn{3}{|c|}{$\begin{array}{c}\text { Precipitação/ } \\
\text { Ultracentrifugação }\end{array}$} \\
\hline & $50 X$ & $100 x$ & $150 x$ & $50 x$ & $100 x$ & $150 x$ & $50 X$ & $100 x$ & $150 X$ \\
\hline $0 \%$ & $\begin{array}{l}\text { Sem } \\
\text { reação }\end{array}$ & Muito fraca & Fraca $^{\mathrm{c}}$ & $\begin{array}{l}\text { Sem } \\
\text { reação }\end{array}$ & Muito fraca & Fraca & $\begin{array}{l}\text { Sem } \\
\text { reação }\end{array}$ & $\begin{array}{c}\text { Sem } \\
\text { reação }\end{array}$ & $\begin{array}{l}\text { Sem } \\
\text { reação }\end{array}$ \\
\hline $2 \%$ & $\begin{array}{l}\text { Muito } \\
\text { fraca }\end{array}$ & Fraca & Boa $^{d}$ & $\begin{array}{l}\text { Muito } \\
\text { fraca }\end{array}$ & Fraca & Boa & $\begin{array}{l}\text { Sem } \\
\text { reação }\end{array}$ & $\begin{array}{l}\text { Sem } \\
\text { reação }\end{array}$ & $\begin{array}{l}\text { Sem } \\
\text { reação }\end{array}$ \\
\hline $5 \%$ & Boa & Excelente ${ }^{*}$ & Excelente ${ }^{* *}$ & Boa & Excelente* & Excelente ${ }^{* *}$ & $\begin{array}{l}\text { Sem } \\
\text { reação }\end{array}$ & $\begin{array}{l}\text { Muito } \\
\text { fraca }\end{array}$ & $\begin{array}{l}\text { Muito } \\
\text { fraca }\end{array}$ \\
\hline
\end{tabular}

** Verifica-se uma segunda linha entre o poço do Ag e do Ac considerada boa

a-Sem reação - sem visualização da linha de precipitação de Ag-Ac

b-Muito fraca- linha de precipitação de Ag-Ac de difícil visualização

c-Fraca - linha de precipitação de Ag-Ac de regular visualização

d- Boa - linha de precipitação de Ag-Ac de boa visualização

e-Excelente - linha de precipitação de Ag-Ac de ótima visualização 


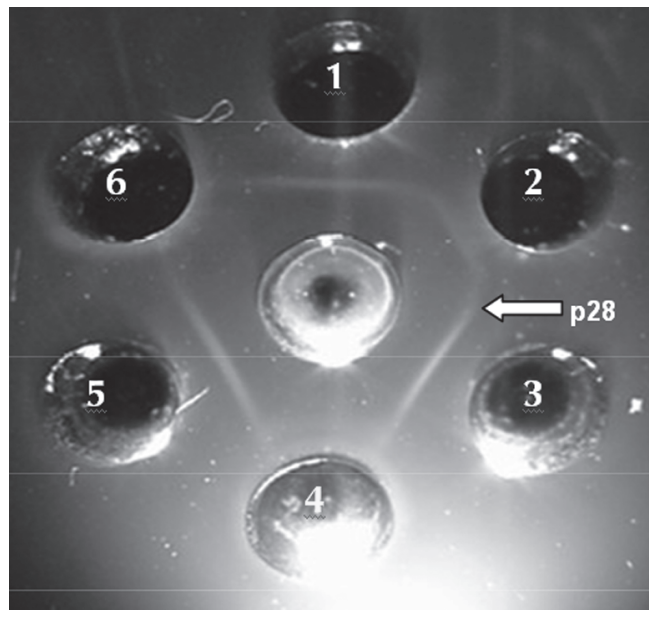

Figura 1 - IDGA do antígeno Ag concentrado $50 \mathrm{X}$ (poço central) método AMICON frente ao soro positivo do kit comercial (poços 1, 2, 3e 5), negativo (poço 4) e fraco positivo (poço 6). Nos poços 1,2, 3 e 5 verifica-se a presença de uma linha de precipitação referente a proteína p28

foi a concentração que apresentou melhor resultado corroborando com os achados de Castro $^{6}$, provavelmente em virtude da maior multiplicação celular, o que estimula a replicação viral ${ }^{14}$, mesmo sabendo que o SFB em grandes quantidades inibe o crescimento viral. Abreu ${ }^{5}$ utilizando Ag preparado com $2 \%$ de SFB e concentração de $50 \mathrm{X}$, por diálise, verificou boas linhas de precipitação.

Nos métodos de concentração diálise e AMICON somente na concentração do Ag de $150 \mathrm{X}$, produzido com SFB 5\%, verificou-se a presença de duas linhas de precipitação referentes às proteínas p28 (Figura 1) e a gp 135 (Figura 2). Em todas as outras situações verificou-se somente uma linha de precipitação referente a proteína nuclear p28. Desta forma, pode-se verificar que ao se concentrar mais o Ag pode-se obter as duas linhas de precipitação. Entretanto, quando se utilizou a concentração de $150 X$ verificou-se que existia um extravasamento de material do poço provavelmente em decorrência de uma alta concentração do Ag que retirava água do próprio gel.

Com relação as concentrações verificou-se que tanto a técnica de membrana

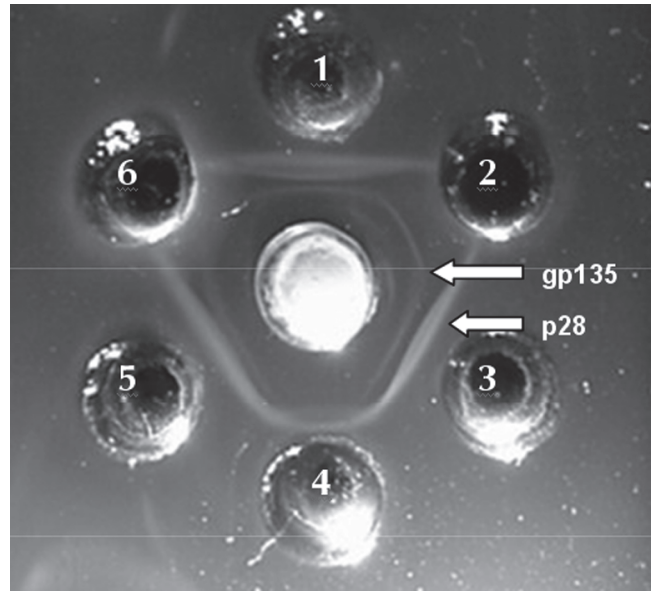

Figura 2 - IDGA do antígeno ag concentrado 150x (poço central) método AMICON frente ao soro positivo do kit comercial (poços 1, 3, 4 e 5), e reagente nos (poços 2 e 6). Nos poços com soro positivos observa-se claramente a formação de duas linhas de precipitação das proteínas gp135 (intema) e p28

de diálise quanto o sistema AMICON apresentaram bons resultados com relação à formação de linhas de precipitação e IDGA, entretanto o sistema $\mathrm{AMICON}$ é mais rápido e reduz as perdas de Ag. Na concentração por precipitação/ultracentrifugação apesar de concentrar até 150 vezes verificou-se apenas linha de difícil visualização.

Utilizando os métodos do AMICON ou concentração por diálise, concentração de $100 \mathrm{X}$ e SFB a $5 \%$ verificou-se que é possível realizar o IDGA detectando as duas principais proteínas do LVC, o que aumenta a sensibilidade do Ag. Adams et al. ${ }^{3}$ identificaram as proteínas p28 e gp 135 como as responsáveis pelas linhas de precipitação observadas na IDGA. Avaliando dois antígenos do LVC (gp 135 e p28) para a detecção de anticorpos através do IDGA, Adams e Gorham ${ }^{16}$ concluíram que o antígeno gp 135 detecta maior número de caprinos infectados do que o antígeno $\mathrm{p} 28$, ainda que alguns animais desenvolvam resposta anti-p28 na ausência de resposta anti-gp 135. A importância da escolha de um antígeno influencia marcadamente os resultados da IDGA no diagnóstico das enfermidades causadas pelo LVC. A 
utilização do antígeno com as duas proteínas (gp 135 e p28) aumenta a sensibilidade diagnóstica do teste. Os autores salientaram, ainda, a importância da escolha dos soros de referência utilizados em testes IDGA para diagnóstico de infecção por LVC.

Com o objetivo de observar como a expressão de anticorpos varia durante o tempo em caprinos soropositivos, Hanson, Hydbring e Olsson ${ }^{17}$ utilizando a IDGA para detectar anticorpos para os antígenos gp135 e p28 do lentivírus MVV, verificaram que a expressão de anticorpos para LVC variou ao longo do tempo, mostrando que reações soropositivas e soronegativas podem ocorrer intermitentemente. Baseado nestes fatos ressalta-se a necessidade da utilização conjunta das proteínas nos antígenos para aumentar a sensibilidade da prova.

\section{Conclusões}

A produção de antígeno nacional para o teste de imunodifusão de gel de agarose é tecnicamente viável. Quanto à quantidade de $\mathrm{SFB}$ a mais indicada durante o processo é de $5 \%$.

Tanto o método do sistema AMICON quanto o da concentração por diálise são indicados, entretanto o sistema AMICON, apesar dos custos de implantação, promoveu maior rapidez e praticidade.

A concentração de 100 vezes permite o diagnóstico da AEC por duas proteínas (gp 135 e p28).

A produção do $A g$ por precipitação e ultracentrifugação, utilizada para provas imunoenzimáticas, não apresentou resultados satisfatórios para o IDGA.

\section{Comparison of three techniques for production goat lentivirus antigen used in the agar gel immunodifusion test}

\section{Abstract}

The Caprine Arthritis Encephalitis (CAE) is a disease who cause considerable economic losses, including loss in the milk production and reduction of the useful life of the animal. In the diagnosis of this disease the agar gel immunodifusion test (AGID) is used worldwide as the selection test. The objective of thid work was to test three different concentrations of bovine fetal serum (BFS) in the production of the antigen $(\mathrm{Ag})$ for the diagnosis of the $\mathrm{CAE}$ virus (CAEV), to verify amongst the three methods the most efficient concentration and which the antigen concentration of the antigen produced is appropriate for the test. The method of the AMICON and the concentration of the $\mathrm{Ag}$ for dialysis was indicated, however the system AMICON, despite the implantation costs, promoted minor loss of antigen, little time expense in the processing and greater simplicity. With relation to the amount of BFS placed after the viral inoculation it was verified that $5 \%$ of BFS the amount that presented better resulted. The antigen concentration 100 times was more indicated, therefore it allowed the diagnosis of the CAEV for two proteins (gp 135 and $\mathrm{p} 28$ ). The concentration of the $\mathrm{Ag}$ for precipitation/ultracentrifugation, used for imunoenzimatic tests, did not present resulted satisfactory used in the AGID.

\section{Referências}

1 HAASE, A. T. Pathogenesis of lentivirus infections. Nature, v. 322, n. 6075, p. 130-136, 1986.

2 HARKISS, G. D.; WATT, N. J. Lentivirus infections and their detection. Goat Veterinary Society Journal, v. 11 , n. 1, p. 19-25, 1990.

3 KNOWLES, D. P. et al. Evaluation of agar gel immunodiffusion serology using caprine and ovine lentiviral antigens for detection of antibody to caprine 
arthritis-encephalitis virus. Journal of Clinical Microbiology, v. 32, n. 1, p. 243-245, 1994.

4 ALVES, F. S. F. Teste de imunodifusão em gel de agarose no diagnóstico da Artrite Encefalite Caprina utilizando antígenos do lentivírus caprino e ovino. Sobral: EMBRAPA-CNPC, 1999, 3 p. (EMBRAPACNPC. Comunicado Técnico, 51).

5 ABREU, S. R. O. Isolamento de um vírus sincicial caprino (amostra RPE-03) e comparação da sensibilidade e especificidade relativas do antígeno Maedi-Visna frente ao antígeno AEC (amostra Cork) em teste de IDGA. 1996. 45 f. Dissertação (Mestrado) Departamento de Medicina Veterinária, Universidade Federal Rural de Pernambuco. Recife, 1996.

6 CASTRO, R. S. Lentivírus de pequenos ruminantes: ensaios imunoenzimáticos, perfil sorológico e inferências filogenéticas. 1998. 132 f. Tese (Doutorado) - Escola de Veterinária, Universidade Federal de Minas Gerais, Belo Horizonte, 1998.

7 REED, L. J., MUENCH, H. A simple method of estimating fifty percent end points. American Journal of Hygiene, v. 27, p. 493-497, 1938.

8 PINHEIRO, R. R. Vírus da artrite encefalite caprina: desenvolvimento e padronização de ensaios imunoenzimáticos (ELISA e Dot-Blot) e estudo epidemiológico no Estado do Ceará. 2001. 115 f. Tese (Doutorado) - Escola de Veterinária, Universidade Federal de Minas Gerais, Belo Horizonte, 2001.

9 CUTLIP, R. C. et al. Immunodiffusion test for ovine progressive pneumonia. American Journal Veterinary Research, v. 38, n. 7, p. 1081-1084, 1977

10 MILLIPORE, S. Ultrafiltration cells. 2003. 31 p. Disponível em: <http://www.millipore.com/ userguides.nsf/docs/99228 >. Acesso em: 2 dez. 2003.

11 HOUWERS, D. J.; GIELKENS, A. L. J.; JAN SCHAAKE, J. An indirect enzyme-linked immunosorbent assay (ELISA) for the detection of antibodies to MAEDIVISNA virus. Veterinary Microbiology, v. 7, n. 3, p.209219, 1982.

12 REIS, J. K. P.; LEITE, R. C. An enzyme-linked immunosorbent assay (ELISA) test for the diagnosis of equine infectious anemia in Brazil. Preventive Veterinary Medicine, v. 20, n. 4, p. 261-267, 1994

13 GOUVEIA, A. M. G. et al. Microimunodifusão em gel de ágar para o diagnóstico sorológico de infecção por lentivírus de pequenos ruminantes. In: CONGRESSO BRASILEIRO DE MEDICINA VETERINÁRIA, 27, 2000, Águas de Lindóia. Anais... Águas de Lindóia: 2000. p. 33. Resumo.

14 NARAYAN, O. et al. Slow virus replication: the role of macrophages in the persistence and expression of Visna viruses of sheep and goats. Journal of General Virology, v. 59, pt. 2, p.345-356, 1982.

15 ADAMS, D. S. et al. Identification of caprine arthritis- encephalitis retrovirus proteins in immunodiffusion precipitin lines. Journal of General Virology, v. 66, n. 5, p. 1139-1143, 1985.

16 ADAMS, D. S.; GORHAM, J. R. The gp135 of caprine arthritis encephalitis virus affords greater sensitivity than the p28 in immunodiffusion serology. Research Veterinary Science, v. 40, n. 2, p. 157-160, 1986.

17 HANSON, J.; HYDBRING, E.; OLSSON, K. A long term study of goats naturally infected with caprine arthritis-encephalitis virus. Acta Veterinary Scandinavica, v. 37, n. I, p. 31-39, 1996. 